\title{
Effects of frequency of maintenance phosphate fertiliser application on dry matter production from permanent pastures
}

\author{
W.H. RISK', L.C. SMITH', A.G. SINCLAIR', P.D. JOHNSTONE', \\ P.W. SHANNON ${ }^{2}$, M.B. O'CONNOR* and L. NGUYEN ${ }^{3}$ \\ 'AgResearch, Invermay Agriculture Centre, Private Bag 50034, Mosgiel \\ ${ }^{2}$ AgResearch, Ruakura Agriculture Centre, Private Bag 3123, Hamilton \\ ${ }^{3}$ AgResearch, Canterbury Agriculture and Science Centre. PO Box 60, Lincoln, New Zealand
}

\begin{abstract}
In a series of 12 field trials located throughout New Zealand annual application of phosphate(P) fertiliser was compared with triennial application using rates which applied the same total amount of $\mathrm{P}$ over 6 years. Test materials were triple supetphosphate (TSP) and Sechura phosphate rock (SPR), both of which were applied annually at rates which provided 0.75 times the calculated maintenance $\mathrm{P}$ requirement $(0.75 \mathrm{M})$ and triennially at $2.25 \mathrm{M}$.For the 12 sites combined there was a significant response to $\mathrm{P}$ fertiliser each year. Application frequency had no significant effect on total DM yield over the 6 year period with either TSP or SPR. A cyclic effect with triennial applications was apparent for both fertilisers, with approximately $2-4 \%$ higher yields in the first year and $2-4 \%$ lower yields in the third year of both 3 year cycles. These results indicate that on well developed pastures a change from annual to triennial application frequency of phosphate fertiliser, with either TSP or slow release SPR, will have little effect on DM production providing the same total amount of $\mathrm{P}$ is applied. This gives farmers the opportunity to make some adjustment to $\mathrm{P}$ fertiliser application frequency according to fluctuations in availability of finance. However, these conclusions do not apply to other nutrients such as sulphur, potassium and trace elements for which annual applications may he necessary.
\end{abstract}

K eywords triple superphosphate, Sechura phosphate rock, phosphate fertilisers, annual application, triennial application, application frequency, reactive phosphate reck

\section{Introduction}

Marked annual fluctuations in the net income of pastoral farmers raises the question of whether the frequency of maintenance fertiliser application can be modified to accommodate fluctuating availability of finance without detriment to pasture production. In particular, what effect does the frequency of application have on production provided the same total amount of fertiliser is applied over several years?

It is often suggested that soluble phosphates are likely to be more susceptible to loss through luxury uptake and fixation in the soil when applied infrequently in large quantities than from smaller regular applications. It is also claimed that slow release fertilisers, particularly reactive phosphate rocks, are better suited to infrequent large applications than soluble phosphates.

There has been little work done to study effects of frequency of application of phosphate fertilisera on developed pasture in New Zealand. During (1984) noted this, and postulated that topdressing at 15-18- or even 24-month intervals may not be inferior to annual application. He also reported that twice-a-year applications of soluble $\mathrm{P}$ fertilisera did not increase pasture production compared with annual application.

Annual and triennial $\mathrm{P}$ applications. giving the same total application of $\mathrm{P}$, were compared in three field trials (Grigg \& Croucbley 1980; Grigg et al. 1982; Grigg \& Thomson 1982.) Total dry matter yields over the trial periods (3 or 6 years) did not differ significantly, but there was generally a small cyclic effect with triennial applications.

On hill country it is often economically desirable to have intervals between topdressing of more than one year. During (1972) reported results from a developing hill country pasture near Wellington where applying $1692 \mathrm{~kg} / \mathrm{ha}$ superphosphate in six equal annual applications, or a single initial application, or an intermediate application in 4 of the years resulted in similar total production from all treatments over the 6 years. The single initial treatment gave highest production in the third and fourth years.

Gregg et al. (1988), in a comparison of application strategies for SPR on Manawatu hill pastures. were. unable to detect any significant differences in DM production over 3 years between $50 \mathrm{~kg} \mathrm{P}$ applied in year 1 and $16.7 \mathrm{~kg} \mathrm{P}$ applied annually.

In this paper we report on an examination of annual and triennial application of two $\mathrm{P}$ fertilisera in a major series of field trials. 
Table 1 Annual and total DM yields ( $\mathbf{k g} / \mathbf{h a}) \cdot$ means of 12 sited

\begin{tabular}{|c|c|c|c|c|c|c|c|c|c|c|}
\hline Treatment & Year(s) & 1 & 2 & 3 & 4 & 5 & 8 & $1-3$ & $4-6$ & $1-8$ \\
\hline Control & & 8194 & 9028 & 7701 & 8208 & 7104 & 8239 & 24923 & 19551 & 44474 \\
\hline TSP Annual & & 8602 & 9910 & 8830 & 7375 & 8331 & 7430 & 27142 & 23135 & 50277 \\
\hline TSP Triennial & & 8875 & 9733 & 8288 & 7788 & 8348 & 7155 & 28896 & 23270 & 50188 \\
\hline SPR Annual & & 8348 & 9582 & 8408 & 7247 & 8387 & 7898 & 28314 & 23331 & 49845 \\
\hline SPR Triennial & & 8559 & 9881 & 8315 & 7421 & 8519 & 7458 & 28538 & 23398 & 49932 \\
\hline SED & & 117 & 122 & 104 & 174 & 141 & 159 & 250 & 327 & 477 \\
\hline
\end{tabular}

\section{Methods and materials}

The trials reported on were part of a national series of forms of phosphate fertiliser trials conducted by the Ministry of Agriculture and Fisheries between 1982 and 1989. Full details of sites, treatments and design are given by Smith et al. (1990) and Sinclair et al. (1990a). In 12 of the 19 trials in the series, triple superphosphate (TSP) and Sechura phosphate rock (SPR) were each applied (a) annually for 6 years at 0.75 times the calculated P maintenance $(\mathrm{M})$ rate, and (b) at $2.25 \mathrm{M}$ at the beginning of Years 1 and 4 of the 6-year trial period. Maintenance phosphate rates for each site were calculated using the MAF phosphate maintenance model (Comforth \& Sinclair 1984). SPR contained $12.8 \%$ total $\mathrm{P}$ and $5.7 \%$ citric-acid-soluble $\mathrm{P}$ and was applied unground (60\% passing through a $150 \mathrm{~mm}$ sieve). TSP contained $20.6 \%$ total P. $19.4 \%$ citric acid soluble P and $18.8 \%$ water soluble P.

The 12 trial sites were located in Northland (5). Waikato (2), Canterbury (2) and Southland (3). They were on established pasture which had been regularly topdressed with superphosphate. Basal dressings of sulphur, potassium and magnesium and some trace elements boron, zinc and copper were applied where considered necessary to prevent their deficiency, At the Waikato and Canterbury sites molybdenum was applied but it was not applied at the other sites.

Small plots were established and managed by mowing with clippings returned. There were three replicates of each treatment in a randomised block design. Herbage DM was recorded at each cut. Methods of statistical analysis have been described elsewhere (Johnstone \& Sinclair 1992).

\section{Results}

Differences between DM yields from annual and triennial treatments were so small that they were hardly ever statistically significant at individual sites. It is only by combining all the trials that there was sufficient power in the experiment to show significant, albeit small, overall effects. From the results there was no reason to believe that the effects of application frequency differed significantly at different sites. although logic dictates that effects should be greater in the more responsive sites. Discussion is therefore limited to general effects for the 12 sites combined.

The cyclic nature of the DM response when fertiliser was applied triennially as compared to annually is illustrated in Figure 1. In the first year of a cycle triennial application of fertiliser resulted in greater DM production than annual application. In the third year of a cycle the situation was reversed. This reversal is highly significant. There is no significant difference between the first and second cycles. However, the size of the standard errors is such that the possibility of quite large differences in the cyclic pattern of the two fertilisers in

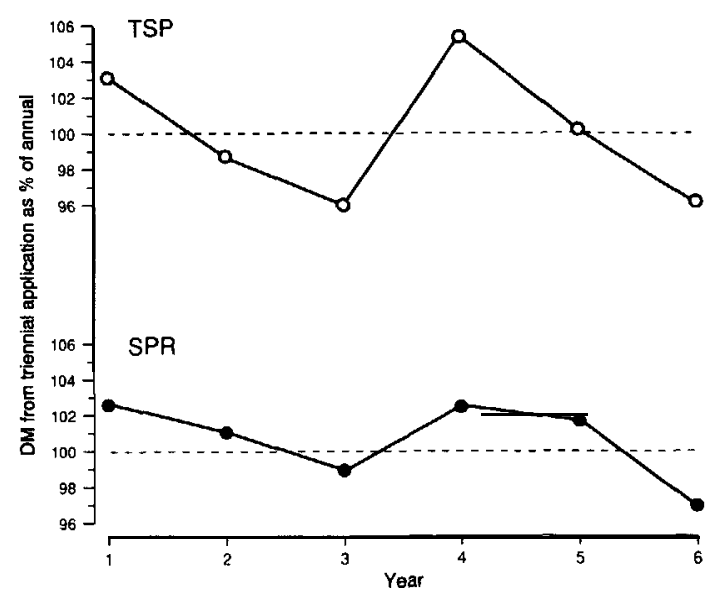

Figure 1 Effect of $\mathrm{P}$ feriliser application frequency on pasture DM production averaged over 12 sites.

the two cycles cannot be ruled out.

Averaged over all 12 sites and the two 3-year cycles, the triennial TSP application produced approximately $4 \%$ more DM than annual TSP in year one of the 3-year cycle, and approximately 4\% less in year three (Table 2). The corresponding percentages for SPR were approximately $2.5 \%$ and $2 \%$ respectively. However, the difference in the amplitudes of the cycles was not significant.

\section{Discussion}

Differences between annual and triennial treatments 
Table 2 Percentage difference (Triennial-annual application) in DM yields averaged over 2 3-year cycles.

\begin{tabular}{cccc}
$\begin{array}{c}\text { Year In } 3 \text { year } \\
\text { cycle }\end{array}$ & 1 & 2 & 3 \\
\hline TSP & +4.2 (SE 1 .56) -0.9 (SE 1.20) & -3.8 (SE 1.20) \\
S P R & +2.5 (SE 1.59) +1.3 (SE 1.23) & -2.1 (SE 1.20) \\
\hline
\end{tabular}

would be expected to be greater in the more responsive sites and could also be affected by site properties such as phosphate retention. However, experimental variability was too great to allow conclusions to be reached as to the effects of these factors on annual versus triennial differences. Consequently discussion must be limited to general effects for the 12 sites combined.

Direct comparisons should not be made between DM yields from TSP and SPR. Sindair et al. (1990b) reported that SPR contained sufficient Mo to remedy Mo deficiency and that some of the 8 sites not receiving basal Mo had apparently deficient Mo concentrations in clover herbage in TSP treatments but not in SPR treatments. Thus some of the response to SPR could be due to its Mo content. Valid comparisons are therefore confined to different application frequencies of the same fertiliser material.

The results indicate that provided the same total amount of fertiliser $P$ is applied, the pattern of application within 3-year periods has negligible effect on total pasture production. This supports and extends the observations of During (1972) and Gregg et al. (1988). Also the cydic effect from infrequent application is small, much smaller than the year to year fluctuations of up to $30 \%$ in DM production due to climatic variability which farmers must cope with (Baars 1981, Raddliffe 1974). Thus provided total $P$ input is maintained in the longer term. farmers have considerable scope to adjust $P$ fertiliser application frequency according to the availability of finance, which has fluctuated sharply over recent years.

These conclusions apply to P only, and not to sulphur, potassium and trace elements which are often incorporated in P fertilisers. Sulphur. in the sulphate form present in single superphosphate and potassium are much more subject to loss by leaching than is $P$, so infrequent application is not appropriate where these are essential components in the $P$ fertiliser. However, elemental sulphur is a slow-release fertiliser suitable for infrequent application.

\section{Conclusion}

Provided the same total amount of maintenance $P$ fertiliser is applied to well-developed pastures there is negli- gible difference in total pasture DM yields between annual and triennial application. There is a small cyclic effect on DM production with triermial application but it is much less than fluctuations caused by climate. These conclusions apply both to soluble $P$ fertiliser (triple superphosphate) and to reactive phosphate rock but they do not apply to other nutrients which may be incorporated in phosphatic fertilisers.

\section{REFERENCES}

Baars. J.A. 1981. Variations in grassland production in the North Island with particular reference in Taranaki. Proceedings of the New Zealand Grassland Association 43: 32-43.

Comforth, I.S.; Sinclair, A.G. 1984. In Fertiliser recommendations for pastures and crops in New Zealand, Second revised edition. Ministry of Agriculture and Fisheries, Wellington, New Zealand.

During, C. 1972. Fertilisers and soils in New Zealand farming. Government Printer, Wellington, New Zealand.

During, C. 1984. Fertilisers and soils in New Zealand farming. Thirdrevised edition. Government Printer, Wellington, New Zealand.

Gregg, P.E.H.; Mackay, A.D.; Currie, L.D.; Syers. J.K. 1988. Application strategies for Sechura phosphate rock use on permanent pasture Fertiliser research 17: 219-234.

Grigg. J.L.; Crouchley. G. 1980. Relative efficiency of phosphatic fertilisers in pasture topdressing II. On a Kokotau silt loam. New Zealand Journal of Agricultural Research 23: 49-65.

Grigg. J.L.; Crouchley, G.; Pownall, D.P. 1982. Relative efficiency of phosphatic fertilisers in pasture topdressing III. Effects on a Rosedale silt loam. Ibid. 25: 565-576.

Grigg. J.L.; Thomson, A. 1982. Relative efficiency of phosphatic fertilisers on pasture topdressing. IV. Effects on a Takapau silt loam. Ibid 25: 577-585.

Johnstone,P.D.; Sinclair, A.G. 1992. Design and Analysis of a National Series of Fertiliser Trials. Proceedings of the XVI International B iometric Conference, Hamilton, NZ: In Press.

Raddiffe, J.E. 1974. Seasonal distribution of pasture production in New Zealand II. Southland Plains. New Zealandjournal of experimental agriculture 2: 341-348.

Sinclair, A.G.; Dyson, C.B; Shannon, P.W. 1990a. The long-term effectiveness of reactive phosphate rock as a phosphate fertiliser for New Zealand pastures. Proceedings of the New Zealand Grassland Association 51: 101-104 
Sindair, A.G;; Shannon, P.W; Risk, WH. 1990b. Sechura phosphate rock supplies plant-available molybdenum for pastures. New Zealand journal of agricultural research 33: 499-502.

Smith, L.C.; Johnstone, P.D.; Sinclair, A.G.; Shannon, P.W.; O'Connor, M.B.; Percival, N.; Roberts, A.H.; Smith, R.G.; Mansell, G.; Morton, J.D.; Nguyen, L.; Dyson, CB.; Risk, W.H. 1990: Final report on the MAF "National Series" forms of fertilisers trials: Part 1 Description of the trials and Annual Herbage Dry Matter Production. Ministry of Agriculture and Fisheries, Wellington, New Zealand. 